\title{
Dynamics of students' opinions concerning problems in the hostel: a sociological analysis
}

\author{
Olga Ganina ${ }^{1, *}$, Vera Fedotova $^{1}$, and Natalya Bolshakova ${ }^{1}$ \\ ${ }^{1}$ Perm National Research Polytechnic University, 614990, 15 Bukireva street, Perm, Russia
}

\begin{abstract}
The article reveals specifics and dynamics of students' views on acute everyday problems in university hostels during the last thirty years. The dynamics of the opinions of students on these issues were analyzed on the basis of the materials of sociological research conducted in the hostels of the Institute of Perm National Research Polytechnic University in 1993 and in 2016. The authors reveal changes in student's life assessments in university hostels through such indicators as key problems in the hostel and priority measures to improve living conditions.
\end{abstract}

\section{Introduction}

Studying the peculiarities of higher education at present is actual in connection with changing its role in the modern society. In the 21st century, the role of information and knowledge is growing. One of the main goals of education is formation of a new generation of high professionals, creation of an accessible environment for information resources and generated knowledge. In the process of education, a multilateral personality develops with a progressive worldview and universal human and professional competences, therefore it is important to investigate different aspects of the life of student youth, as well as the conditions under which their activities take place. The process of learning and its effectiveness largely depends on the housing and living conditions of students.

Analyzing peculiarities of students' opinions on specific housing and communal issues is important for establishing an effective dialogue between the university administration and students living in hostels, as well as with the aim of adequate assessing the trends in changing living conditions and the necessary further measures. With the time passing, the living conditions in the hostels are changing markedly, besides, the students themselves are changing as a social group, and, therefore, their perception of the basic problems of the hostel life.

\section{Literature review}

In the literature, students and their issues are studied quite actively. L. Ya. Rubina, Yu. R. Vishnevsky on the basis of research conducted in 1995 describe the student's social portrait, their socio-professional self-determination, activities and way of life [1,2].

\footnotetext{
* Corresponding author: ganinaoa@yandex.ru
} 
Later, sociological monitoring was conducted from 1995 to 2012, and a compendium edited by $\mathrm{Yu}$. R. Vishnevsky describing the value orientations of students, as well as practices of their educational, public and leisure activities was published.

Also, the issues of students' social activities were studied by M. E. Petrova [3], G. V. Bobrova [4], E. M. Kharlanova [5]. In 2014, E. G. Chernikova [6] investigated the problems of student self-government, and A. I. Vishnyakov, O. S. Karymova, E. A. Trifonova revealed ethnic characteristics of students' values in 2015. In Perm Krai, L. N. Kurbatova, V. N. Stegniy [7, 8], V. D. Razinskaya [9] studied the characteristics of students as a social group.

In 2000-2012 in Moscow, the monitoring "Russian university through the eyes of students" was held. The results of the study concerned the socio-economic status of students and the activity of students in various fields [10].

Among Western studies one can mention such authors as Stebbins and Eisenstadt. Stebbins studied the leisure of young people, highlighting activities, which cause satisfaction and the possibility of self-realization. Eisenstadt considered the culture of young people and their leisure activities. Students actions, communities and partnerships were studied in detail by Boren and Maurrasse [11]. Unsatisfactory satisfaction with living conditions in hostels was investigated by Jean-Luc Mogenet and Liliane Rioux [12].

Despite the diversity and multiplicity of research in this field, there are few studies devoted to the characteristics of students' living conditions in university hostels and the influence of these conditions on students' life.

\section{Materials and methods}

In this paper, we relied on the results of two studies: a survey of students in the hostels of the university in 1993 and in 2016.

In 1993, in the hostels of PNRPU a study was conducted "Some sociological problems of higher education" [13, p. 16]. In 1993, 173 people were interviewed, it was a sample survey by questionnaire. The sample is fairly representative, the respondents lived in different types of university hostels. $63 \%$ and $37 \%$ of the respondents lived in the hostels of the corridor and block type, respectively. The study identified the most acute issues of student life in the hostel, some problems of the educational process, student's ideas about the possibilities of self-government.

In 2016, a sample survey using questionnaires "Students' period as the first stage of adult life" was held in the PNIPU hostels. About 608 respondents were interviewed. Respondents lived in university hostels with different housing conditions. One third of respondents $(36.2 \%)$ lived in the campus "Balatovo" in the hostels of the corridor type, with the earliest year of construction. Another third of the respondents $(36.3 \%)$ lived in block hostels in the campus "Complex". Almost a quarter of the respondents $(23.4 \%)$ were residents of the new type of hostels in the campus "Complex" and $4.1 \%$ lived in other hostels of the University.

Among the main tasks of this study were examination of interpersonal relations, student self-government, identification of housing and living conditions, budget of time and types of students' activities, analysis of students' social activity, identification of their values and socio-psychological characteristics.

Both studies measured students' opinions about the degree of their satisfaction with various aspects of life in the hostel, as well as about the proposed priority measures to improve living conditions. However, the wording of the questions and the proposed answers were somewhat different. 


\section{Dynamics of students' opinions regarding problems in the hostel and priority measures to address them}

Based on the materials of the studies carried out in 1993 [13] and in 2016, it is possible to determine changes in the students' opinions about the most pressing problems in the hostel life and measures for their resolution that have occurred in almost a quarter of a century. There is a decrease in the anxiety of modern students on the problems that were the most acute over 20 years ago. So, unlike in 1993, in 2016 in the university hostels there was no water supply problem, whereas it was the most urgent problem (77\%) in 1993. The relevance of the heat supply problem still remains, although earlier it was noted by $2 / 3$ of respondents $(65.1 \%)$, and now by about half of them (46.7\%).

There is a significant decrease in the relevance of the problem of public order violations by unauthorized persons - in 1993 this problem concerned half of the students in the hostel (47.7\%), and in 2016 they are 8 times fewer - only 6.4\%. Discontent of students with lack of cultural leisure (from $34 \%$ to $11 \%$ ), drunkenness (from $36 \%$ to $8 \%$ ), and lack of conditions to prepare for classes (from $24 \%$ to 6\%) decreased by 3-4 times. The share of those dissatisfied with sanitary and hygienic conditions decreased twice from $65 \%$ to $32 \%$.

On the other hand, in 2016, problems that were not observed in 1993 became very urgent for students, such as a lot of prohibitions, restrictions (37\%), and too strict supervision on the watch $(32 \%)$.

In terms of hostel types (see Fig.1), it is noted that the heat supply and lack of cultural leisure in 1993 worried more students from the corridor type hostels, and in 2016 - students from the block hostels complained about it. The proportion of those dissatisfied with the sanitary and hygienic conditions in the hostels of the corridor type was and remains higher than in the block hostels.

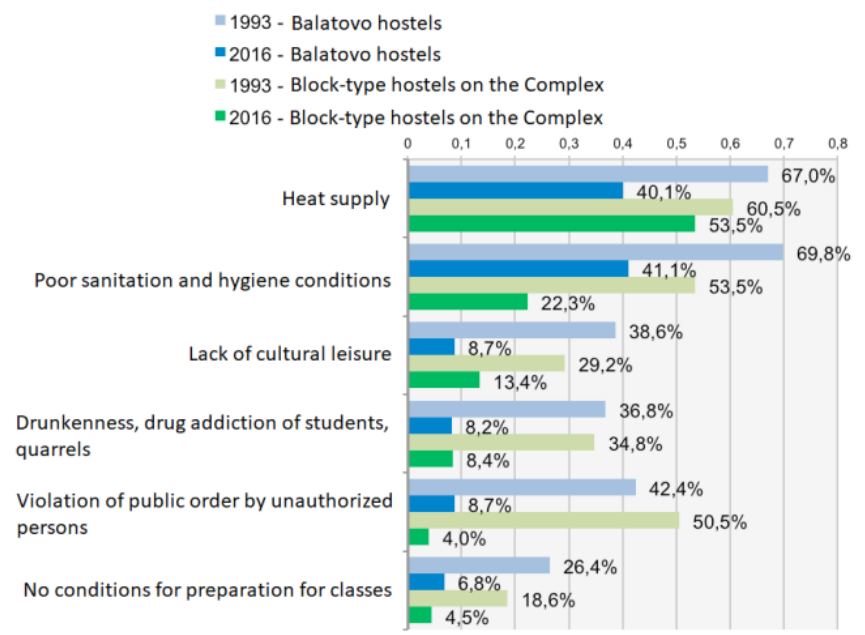

Fig. 1. Dynamics of main problems in the hostel, depending on the type of living conditions, in $\%$ of groups by hostel type.

Violations of public order by strangers in 1993 were noted more often by students from block hostels at the Complex, and in 2016 - in corridor-type hostels in Balatovo. The share of students who were dissatisfied with alcoholism in 1993 was at the same level in the hostels of the corridor and block types, and by 2016 it has decreased equally in both types of hostels. 
The proposals of students in connection with the necessary measures to restore order in the hostel have also undergone noticeable changes over the past twenty years (see Fig 2). Most of all, namely, 5 times the number of proposals to demand more from the hostel staff of the hostel reduced (from $56 \%$ to $11 \%$ ). The number of proposals for eviction of those who do not have the right to reside in the hostel reduced by three times (from 54\% to $17 \%$ ).

Almost twice less there are those who, as a matter of priority, offer to organize a student operational detachment to control order in the hostel (from $28 \%$ to $16 \%$ ) and re-elect the student. council (from $20 \%$ to $11 \%$ ).

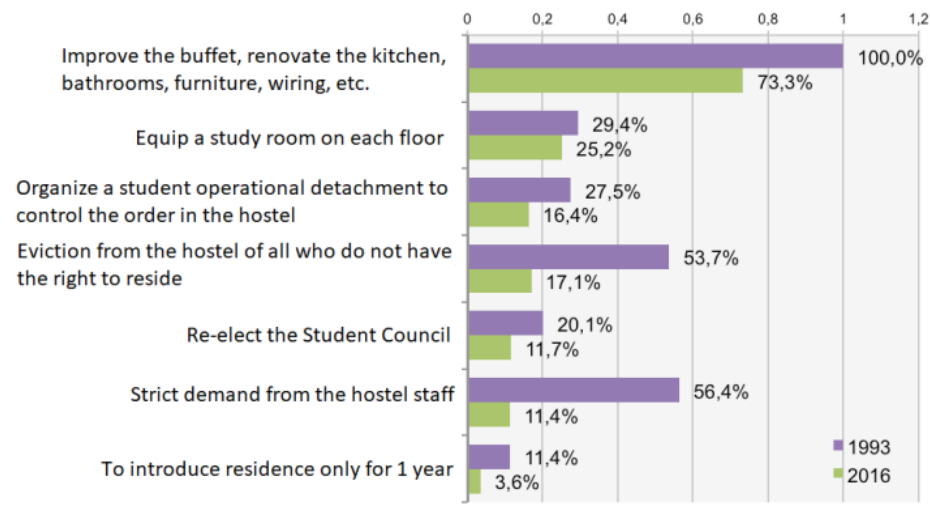

Fig. 2. Dynamics of students priority measures to restore order in the hostel, in $\%$ of the number of respondents.

The option "To take care of the buffet, to repair kitchens, bathrooms, furniture, wiring, etc." in 1993 was divided into two options: "Take care of buffets in hostels," which was noted by $42.3 \%$ of respondents, and " Repair kitchens, bathrooms, furniture, etc. ", which was noted by $74 \%$ of respondents (respondents could choose several answers). In this regard, presumably, the combined version of the answer would have scored $100 \%$ in 1993.

The students' need for study rooms in hostels has remained practically at the same level as twenty years ago (29\% in 1993 and $25 \%$ in 2016).

However, when considering the situation in different types of hostels, it was revealed that during this period the proportion of those who asked to equip study rooms in corridortype hostels in Balatovo decreased, and in block hostels, on the contrary, it increased.

In 1993, proposals to evict people who do not have the right to reside, to introduce residence for 1 year and to demand more severely from the staff of hostels were more frequent in block hostels at the Complex, and in 2016 - on the contrary, all these measures were more often offered by students of corridor-type hostels in Balatovo. Reelection of the student councils in 1993 was also more often offered in block hostels at the Complex, and in 2016 - in corridor-type hostels in Balatovo, while the share of these proposals in the hostels of Balatovo almost has not changed in twenty years, and at the Complex was reduced 4 -fold.

\section{Conclusion}

The most acute problems in the hostels of PNRPU are heat supply, a lot of prohibitions and restrictions and too strict control on the watch. In addition, the problems of poor sanitary and hygienic conditions and overcrowding are quite relevant for students. For a quarter of a century from 1993 to 2016, such problems of life in the hostel as water supply, violations of public order by outsiders, lack of cultural leisure, drunkenness and the lack of conditions 
for preparation for classes have lost their relevance. During the same period, the share of people who were dissatisfied with sanitary and hygienic conditions decreased by half. Slightly decreased, but still urgent is the problem of heat supply. And the problems so widespread in 2016, as a lot of prohibitions and restrictions and too strict control on the watch, were not observed in 1993.

Among the first-priority measures to restore order in the hostel, most often noted are the need for a buffet, repair of kitchens, bathrooms, replacement of furniture and electrical wiring, as well as equipping study rooms on each floor. These proposals have not lost their relevance for almost a quarter of a century, but there are some changes. In 2016, in comparison with 1993, the share of proposals to demand more strictly from the hostel staff reduced by 5 times. The share of proposals for eviction of people who do not have the right to reside reduced three times. The proposals to organize a student operational detachment to control order in the hostel and re-elect the student council reduced twice.

For a quarter of a century from 1993 to 2016, the problem of water supply which was the most widespread has disappeared from the list of actual problems of life in the hostel. The problem of disturbance of public order by unauthorized persons (in 1993 - 48\%, and in 2016 only $6 \%$ ) has lost its relevance. The discontent of students with a lack of cultural leisure (from $34 \%$ to $11 \%$ ), drunkenness (from $36 \%$ to $8 \%$ ), and the lack of conditions to prepare for classes (from 24\% to 6\%) has decreased 3-4 times. Twice the share of those dissatisfied with sanitary and hygienic conditions has decreased from $65 \%$ to $32 \%$.

However, the urgency of the problem of heat supply is still quite high, although earlier it was noted by $2 / 3$ of the respondents, and now by about half of them. Among the new problems that were not noted in 1993, a lot of prohibitions and restrictions (37\%) and too strict control on the watch (32\%) are very widespread in 2016.

Compared with the students' proposals on the necessary measures to restore order in the hostel in 1993, the share of proposals to demand more strictly from hostel staff in 2016 has reduced by 5 times, the share of proposals for eviction of people who do not have the right to reside, has reduced threefold. Finally, there are twice as few proposals to organize a student operational detachment to control order in the hostel and re-elect the student council. At the same level, there is a need for study rooms (29\% in 1993 and 25\% in 2016).

\section{References}

1. Yu. R. Vishnevsky, L.Ya. Rubina, Socis, 10 (1997)

2. Yu. R. Vishnevsky, V. T. Shapko, Student-95: A social portrait (SVAPOS, Ekaterinburg, 1995)

3. M. E. Petrova, Service Plus, 3 (2011)

4. G. V. Bobrova, Psychology and Pedagogics, 23 (2011)

5. E. M. Kharlanova, Historical and Social-Educational Thought, 5 (2011)

6. E. G. Chernikova, Bulletin of Chelyabinsk State Pedagogical University, 4 (2014)

7. V. N. Stegniy, L. N. Kurbatova, Social portrait of students under conditions of transformation of the Russian society (PSTU, Perm, 2009)

8. V. N. Stegniy, Vestnik PNRPU: Social-Economic Studies, 3 (2016)

9. V. D. Razinskaya, Vestnik PNRPU: Social-Sconomic Studies, 3 (2016)

10. Yu. R. Vishnevsky, Student - 2012 (UrFU, Ekaterinburg, 2012)

11. B. Stockdill, D. Stockdill, Qualitative Sociology, 26, 4 (2003)

12. J.-L. Mogenet, L. Rioux, Nordic Psychology, 66, 4 (2014)

13. Some sociological problems of the higher education (PSTU, Perm, 1993) 